\title{
Evaluation the fitness of anthropometric dimensions of students the best-selling laptop desks
}

\author{
M. Jafarvand ${ }^{1}, \underline{\text { S. } \operatorname{Varmazyar}^{1}}$, MA. Hematgar ${ }^{1}$, M. Rezapour ${ }^{1}$
}

\author{
${ }^{1}$ School of Health, Qazvin University of Medical Sciences, Qazvin, Iran \\ Corresponding Address: Sakineh Varmazyar, School of Health, Qazvin University of Medical Sciences, Shahid Bahonar \\ Blvd., Qazvin, Iran. \\ Tel: +98-28-333600; Email: Svarmazyar@qums.ac.ir \\ Received: 20 Jul 2017; Accepted: 5 Oct 2017
}

\section{* Abstract}

Background: The fitness of laptop desks (sitting cross-legged) with physical dimensions of users have important role in using with correct posture and reduce the prevalence of musculoskeletal disorders.

Objective: The aim of this study was to evaluate the fitness of anthropometric dimensions of students with best-selling laptop desks.

Methods: In this study, 207 students (girls and boys) from Qazvin University of Medical Sciences were investigated. In addition to height and weight, anthropometric dimensions including; elbow height (sitting), elbow-elbow breadth, two knee length and height (sitting position cross-legged) and elbow-fingertips length were measured. Then percent of the fitness between the laptop desks with anthropometric dimensions obtained.

Findings: The results showed that the two types of laptops desks fit only in the length of the desk. Two knee length and height (sitting position cross-legged), elbow - fingertips length and elbow height (sitting) fit in the desk number one 32.4, 98.5, 0 , and $93.7 \%$ and in the desk number two $61.8,0.96,0.5$, and $78.3 \%$ respectively.

Conclusion: It had a $100 \%$ fitness only in length of the table with anthropometric dimensions of students between two types of laptop desks. However in terms of fitness, the desk number one with the highest percentage in three anthropometric dimensions was better than the desk number two.

Keywords: Ergonomic, Anthropometry, Physical fitness, Laptop desk, Posture, Musculoskeletal diseases

Citation: Jafarvand M, Varmazyar S, Hematgar MA, Rezapour M. Evaluation the fitness of anthropometric dimensions of students the best-selling laptop desks. J Qazvin Univ Med Sci 2018; 22(3): 68-76. 


\title{
ارزيابى ميزان تطابق ابعاد آنترويومتريكى دانشجويان با ميزهاى لٍ تاٍ يُرفروش موجود
}

\author{
مجتبى جعفروند'، دكتر سكينه ورمزيار' '، محمدامين همت كر '، مر تضى رضايور'
}

' دانشكده بهداشت دانشكاه علوم يزشكى قزوين، قزوين، ايران

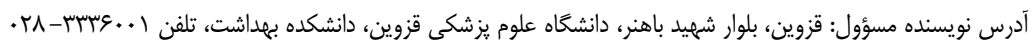
تاريخ دريافت:

زمينه: تناسب ميزهاى لٍ تِاي (حالت نشسته جههار زانو) با ابعاد بدنى كاربران، نقش مهمى در استفاده بـا وضـعيت بــنى صـحيح و كـاهش شـيوع اختلالات اسكلتى - عضلانى دارد.

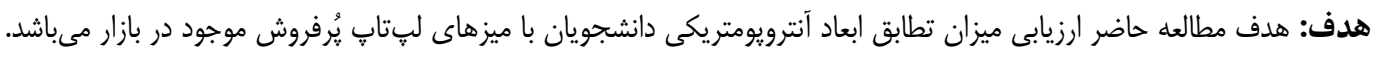

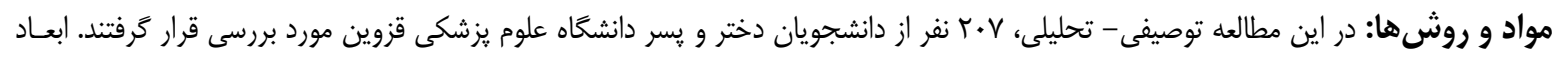

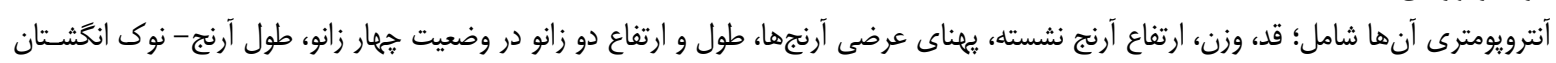

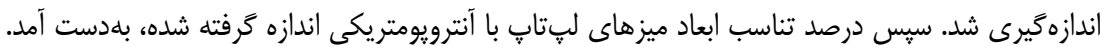

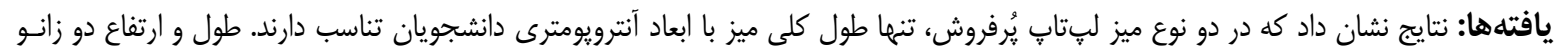

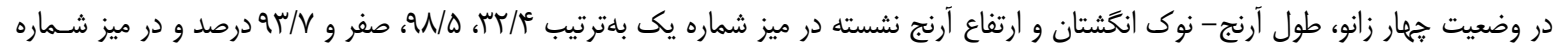

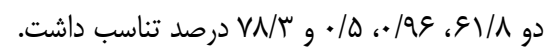

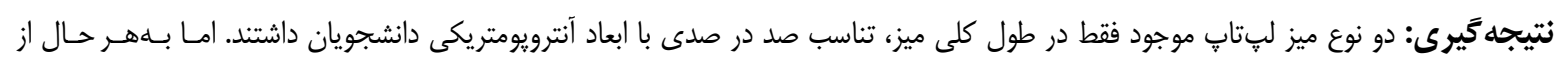

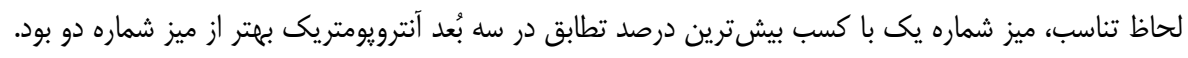
كليدوازْها: ارگَونومى، آنترويومترى، تناسب فيزيكى، ميز لٍتاب، وضعيت بدنى، اختلالات اسكلتى - عضلانى

ارگونومى در يى انطباق محيط كار و زندگى انسـان از نظر شاخصهاى آنترويومترى است. با استفاده از اين علم

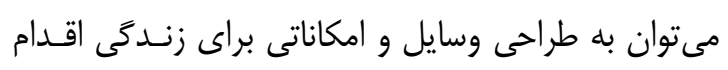

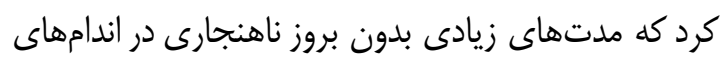

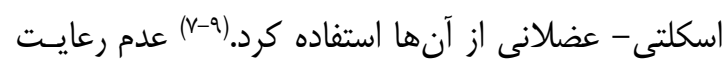

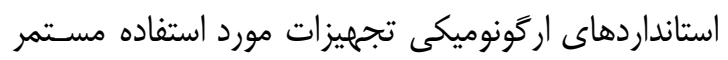

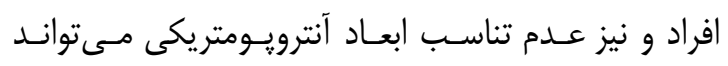

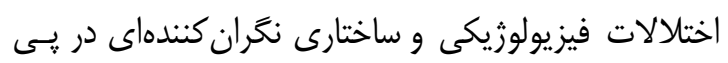
داشته باشد كه در مفاهيم ارگونـوميكى از آن بـهـ عنـوان خستخى و نار احتى نام برده مىشود.(و.|r--1)

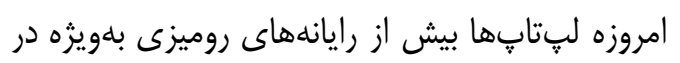

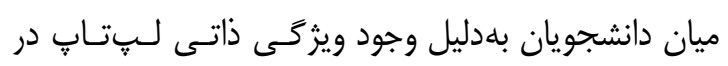

مقدمه: بسيارى از شواهد بهويزه در كشورهاى در حـال رشـــ صنعتى نشان داده است، فقدان تناسب ميان تكنولـوزى و استفاده كننده از آن در محيطى كه تكنولوزى در آن بهكـار

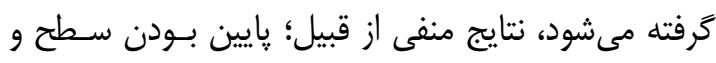

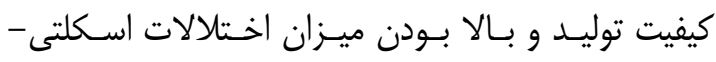
عضلانى ناشى از كار را در يـى داشته است. نكته اصلى در طراحى تجهيزات اين است كه تجهيزات براسـاس اصـول

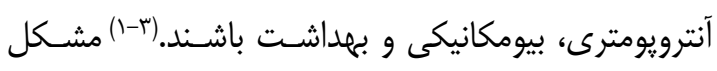
اصلى جهت دستيابى به طراحى مناسـب و هماهنـ بـ بـا

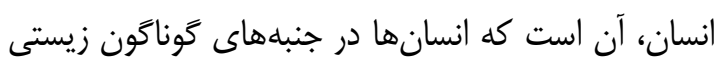

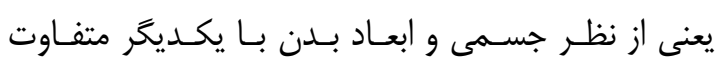
هستند. (9-8) 
تماس هستند؛ اصول طراحى ارگَونوميكى در ابعاد، اندازهها و زوايا رعايت شود تا اين صدمات كاهش يابند.

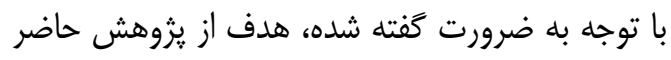

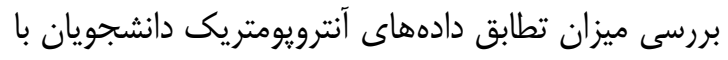

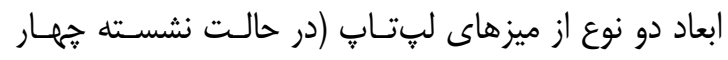

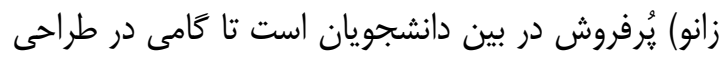
بهتر اين نوع ميزها برداشته شود.

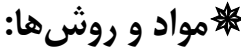

اين مطالعه كاربردى بلهصورت توصـيفى - تحليلى در

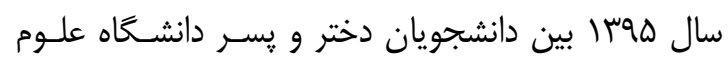

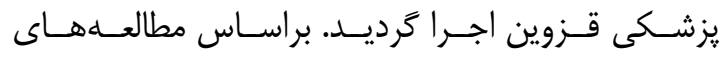

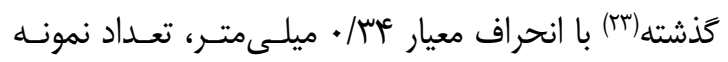

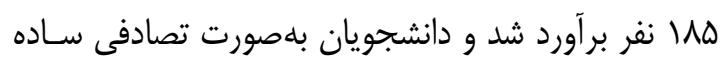

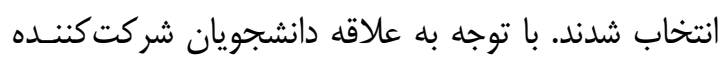

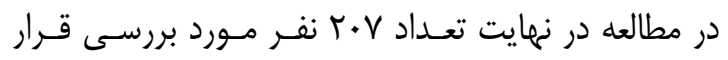

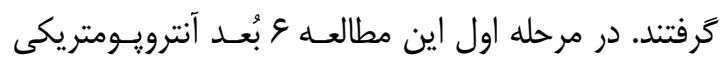

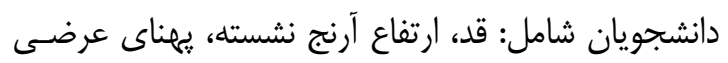

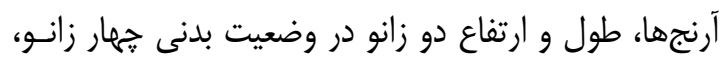

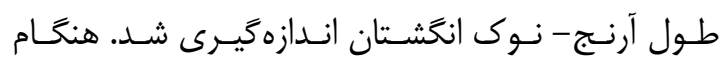

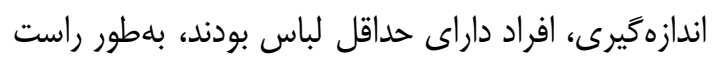

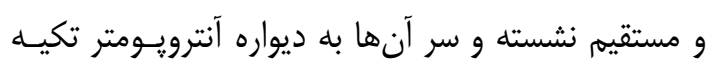

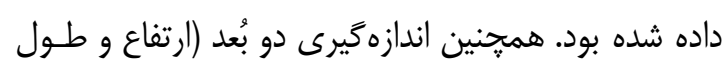

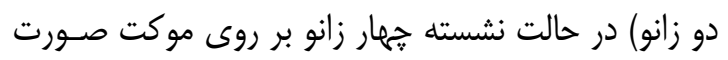

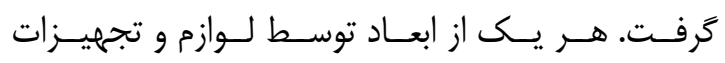

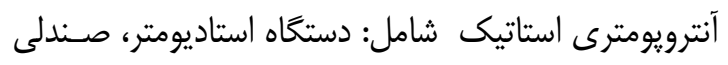

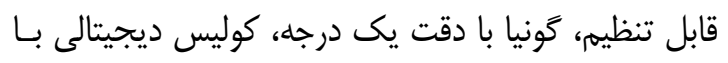

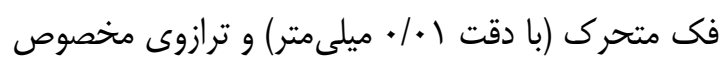

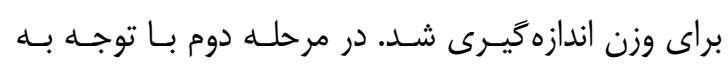

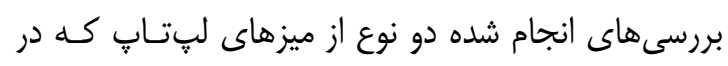

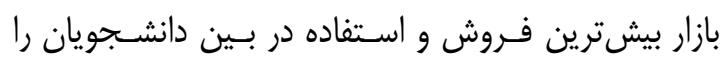

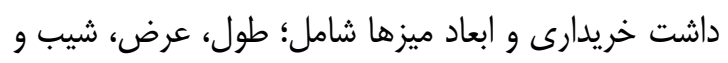

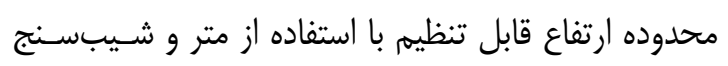

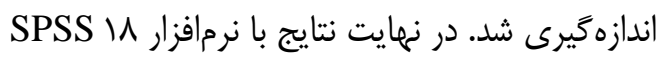

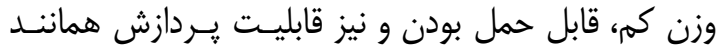

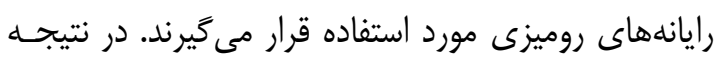

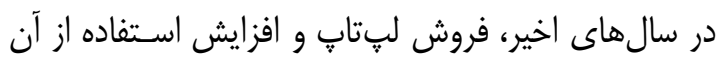

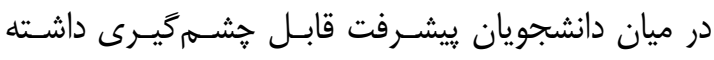

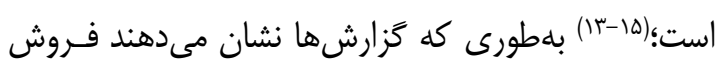

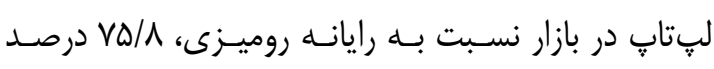
افزايش در ميان دانشجويان و فارغالتحصيلان جامعه يِيـا

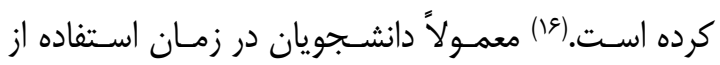

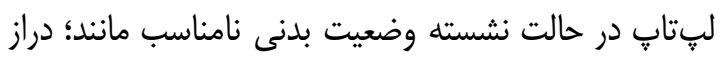

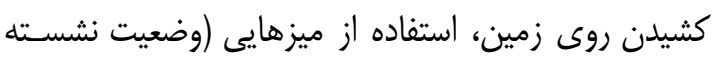

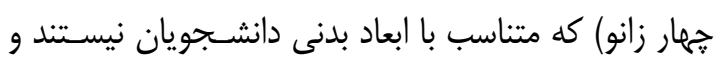

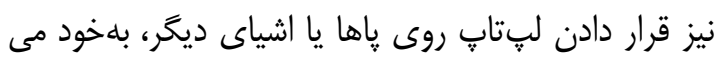

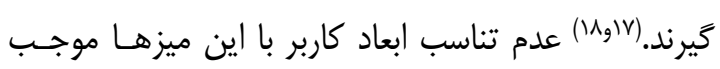

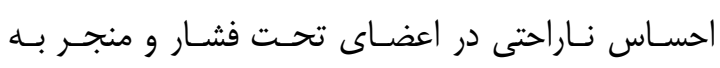

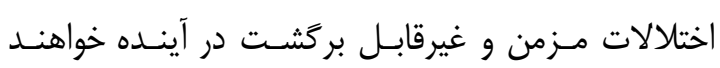
شد. (r. (r) (r)

يزوهش انجام شده توسط مافت و همكاران با موضوع

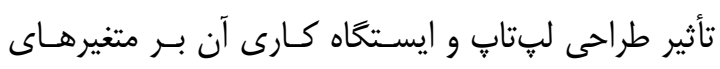

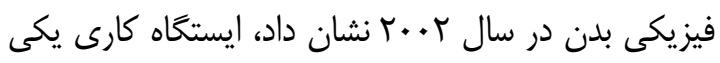

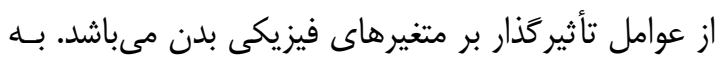

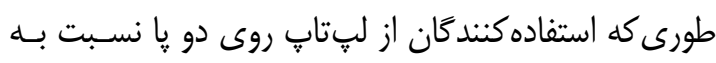

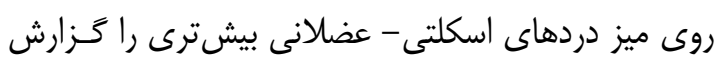

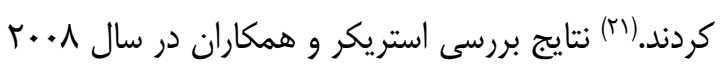

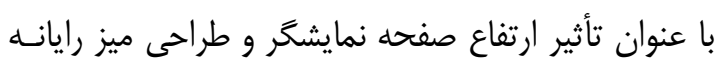

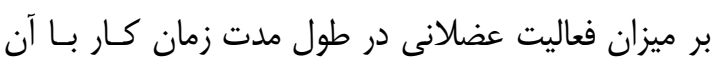

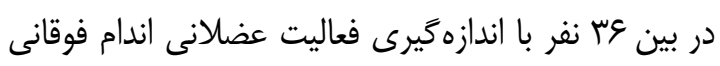

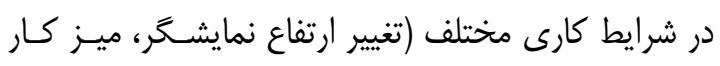

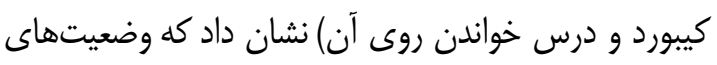

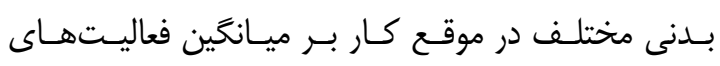

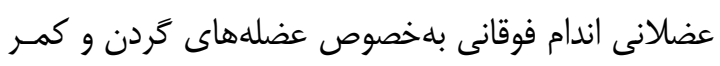

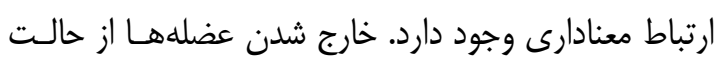

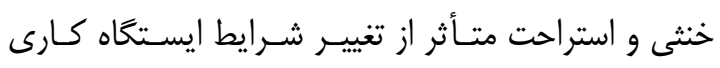

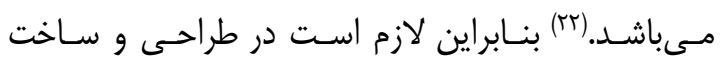

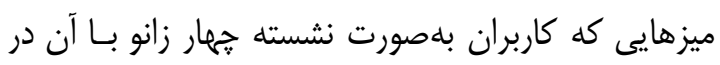




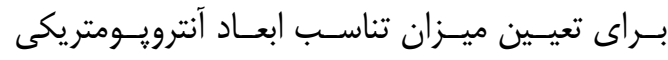

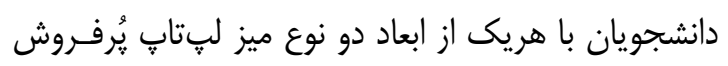
يافتهها:

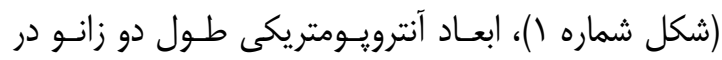

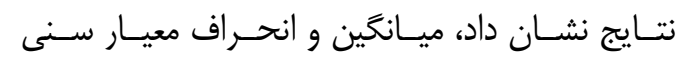

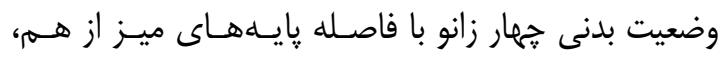
دانشجويان مورد مطالعه

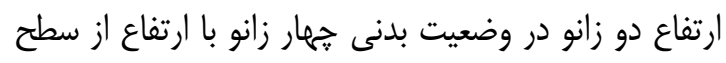

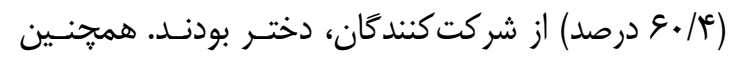

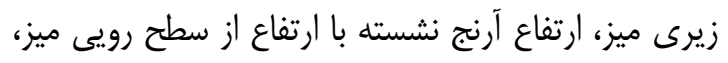

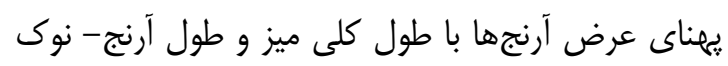

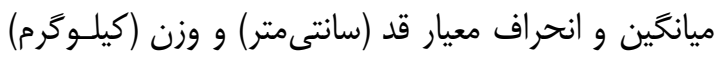

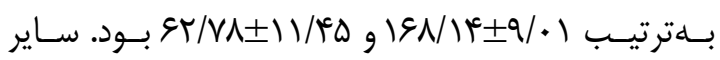

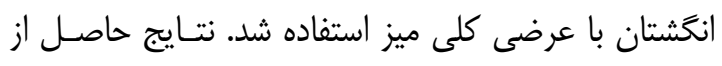

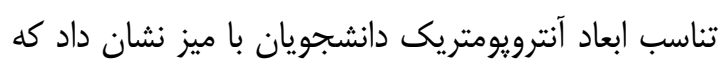
ويثزى هاى جمعيت شناختى افراد مورد مطالعـه در جـدول ا ذانر شده است.

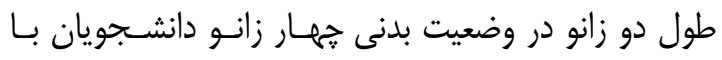

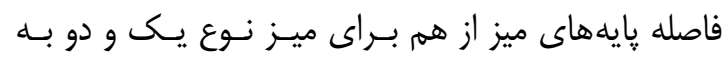

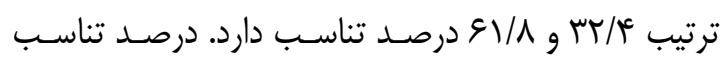

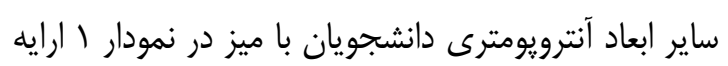
شده است.

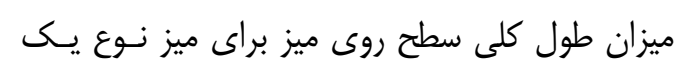

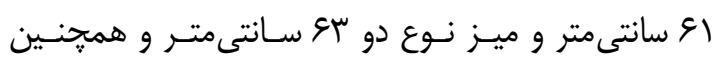

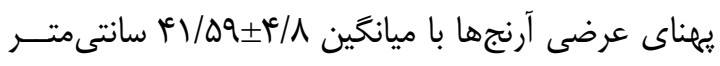

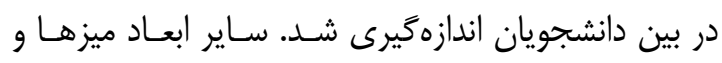

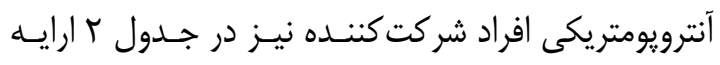

جدول ا - مشخصات جمعيت شناختى افر اد شركت كننده (n=r (

\begin{tabular}{|c|c|c|c|}
\hline درصد & تعداد & متغير & \\
\hline $\mathrm{rq/8}$ & NT & "ֶسر & \multirow{2}{*}{ جنس } \\
\hline $9 \cdot / 4$ & ITa & دختر & \\
\hline $9 / v$ & r. & اتاق عمل & \multirow{12}{*}{ تحصيلى رشته } \\
\hline$r / \pi$ & pe & بهداشت حرفهاى & \\
\hline$N / r$ & IV & بهداشت محيط & \\
\hline$V / T$ & 10 & بهداشت عمومى & \\
\hline $9 / \mathrm{V}$ & r. & 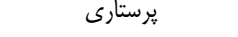 & \\
\hline $1 / 9$ & r & 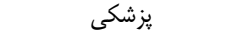 & \\
\hline$r / 4$ & $\Delta$ & 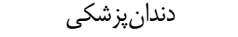 & \\
\hline$N / T$ & IV & علوم أزمايشكاهى & \\
\hline $1 \cdot / 1$ & r) & فوريتهاى بزشكى & \\
\hline$\Delta / \Lambda$ & ir & مامايى & \\
\hline $9 / \mathrm{V}$ & r. & مديريت خدماتى و بهداشتى & \\
\hline$\Delta / \Lambda$ & ir & 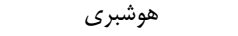 & \\
\hline
\end{tabular}


جدول ז- مشخصات ابعاد آنترويومتريك دانشجويان و ميزهاى لٍٍتاب يُرفروش موجود (برحسب سانتىمتر يا درجه)

\begin{tabular}{|c|c|c|c|c|c|c|}
\hline حداكثر - حداقل & انحراف معيار 土ميانگين & ابعاد آنترويومتريك & نوع r & نوع & \multicolumn{2}{|c|}{ يارامترهاى ابعادى ميزها } \\
\hline$r \Delta / \Delta T-9 \Delta / / Q$ & $\digamma \uparrow / \Delta q \pm \digamma / \Lambda$. & يميناى عرضى آرنجها & $9 \pi$ & 91 & \multicolumn{2}{|c|}{ طول كلى سطح رويى ميز } \\
\hline$r F / T \cdot-\Delta T / \mu G$ & $F \Psi / \mu V \pm \Psi / T r$ & طول آرنج - نوك انخشتان & ro & re & \multicolumn{2}{|c|}{ عرض كلى سطح رويى ميز } \\
\hline$\lceil\backslash / \Gamma \Delta-\Lambda 1$ & $\Delta N / I V \pm \varepsilon / N^{C}$ & طول دو زانو در وضعيت جهار زانو & 9. & $\Delta F / \Delta$ & \multicolumn{2}{|c|}{ فاصله پايههاى ميز از هم } \\
\hline \multirow{2}{*}{ | } & \multirow{2}{*}{$r E / \Delta \cdot \pm T / \Lambda r^{c}$} & \multirow{2}{*}{ ارتفاع آرنج- نشسته } & rq & $r \cdot$ & حداقل & \multirow{2}{*}{ ارتفاع قابل تنظيم كل } \\
\hline & & & $4 \varepsilon$ & r & حداكثر & \\
\hline \multirow{2}{*}{ שr- } & \multirow{2}{*}{$r M / V I T / \Delta$. } & \multirow{2}{*}{ ارتفاع دو زانو در وضعيت هِهار زانو } & $M$ & M & حداقل & \multirow{2}{*}{ ارتفاع قابل تنظيم كل } \\
\hline & & & M & rq & حداكثر & \\
\hline \multirow{2}{*}{-} & \multirow{2}{*}{-} & \multirow{2}{*}{-} & صفر & $r / 4$ & حداقل & \multirow{2}{*}{ صفحه ويڤّه لٍتابٍ } \\
\hline & & & Tr & $\mathrm{V} / \mathrm{A}$ & حداكثر & \\
\hline \multirow{2}{*}{-} & \multirow{2}{*}{ - } & \multirow{2}{*}{-} & صفر & $r / 9$ & حداقل & \multirow{2}{*}{ صفيب قابل تنظيم } \\
\hline & & & صفر & $\mathrm{V} / \mathrm{\Lambda}$ & حداكثر & \\
\hline \multirow{2}{*}{-} & \multirow{2}{*}{-} & \multirow{2}{*}{-} & is & ندارد & طول & \multirow{2}{*}{ ابعاد صفته ويرّه } \\
\hline & & & ro & ندارد & عرض & \\
\hline \multirow{2}{*}{-} & \multirow{2}{*}{ - } & \multirow{2}{*}{-} & iv & ندارد & طول & \multirow{2}{*}{ ابعاد صفحه ويثره } \\
\hline & & & ro & ندارد & عرض ع ع & \\
\hline
\end{tabular}

نمودار ا - درصد تناسب ابعاد آنترويومتريك دانشجويان با ميزهاى لٍ تاٍ يُرفروش موجود

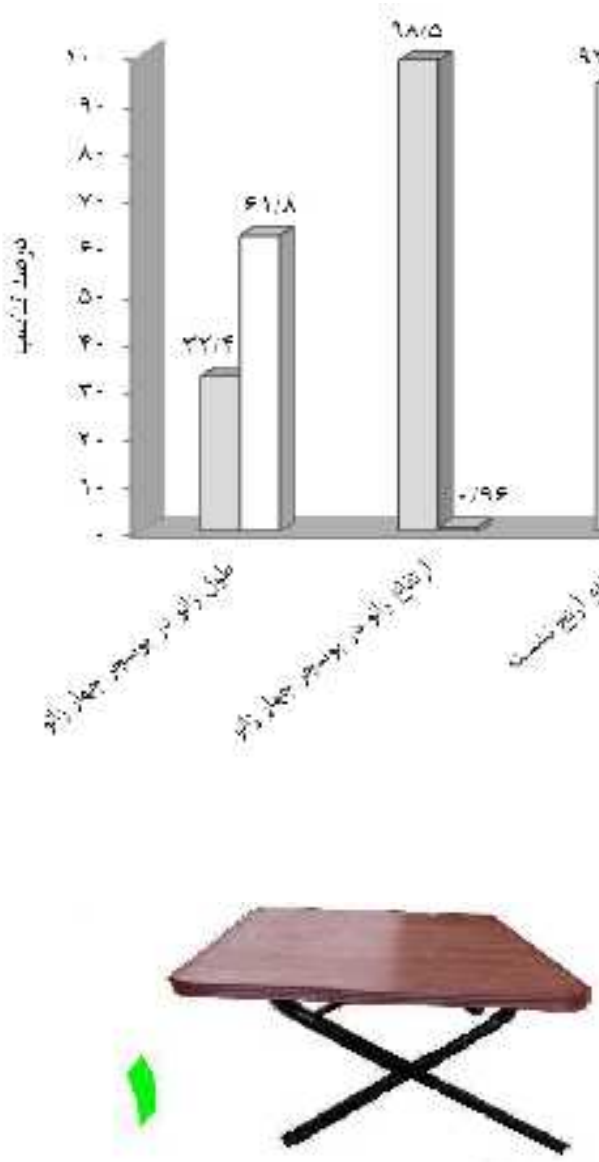

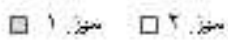
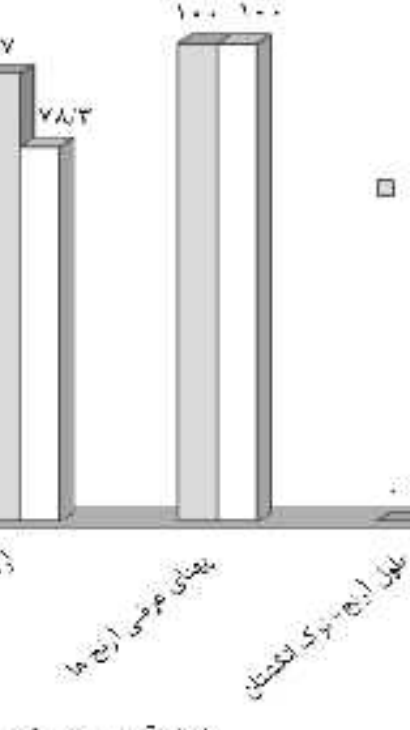

ابماد آنترويومثريك

شكل ا - ميزهاى لٍ تاب يُرفروش موجود در بازار 
داراى مقادير برابر مىباشد.(F) ميـز شـماره يــ قابليـت

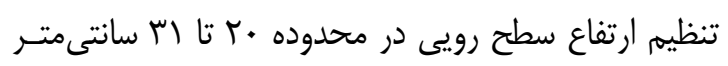

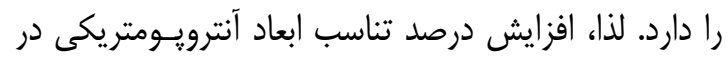

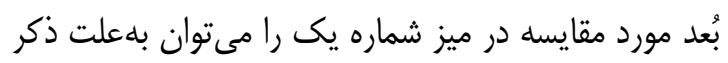

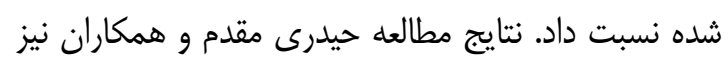

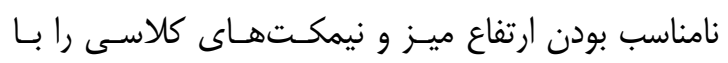

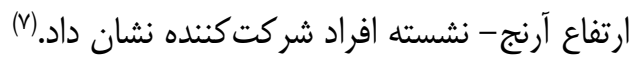

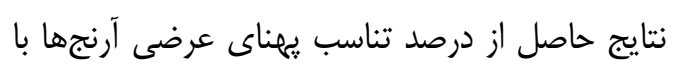

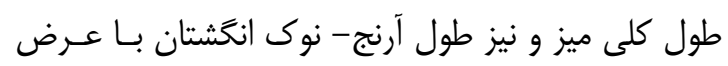

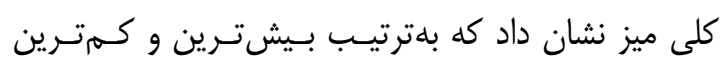

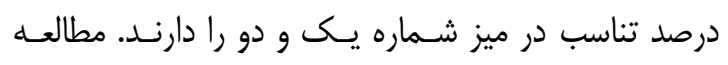

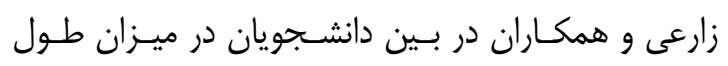

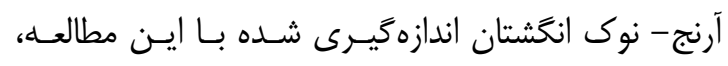

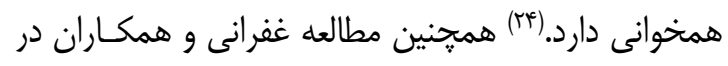

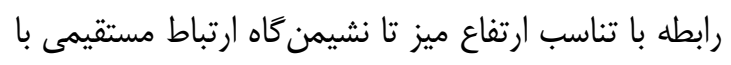

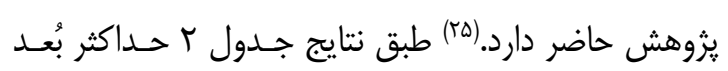

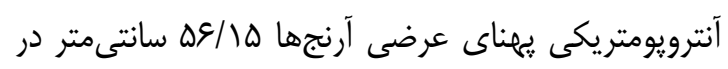

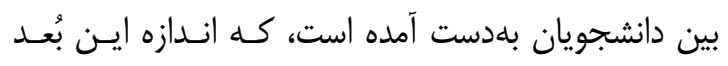

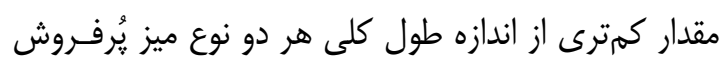

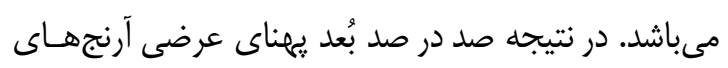

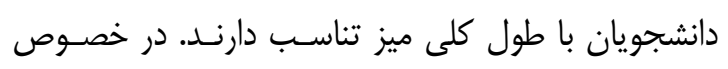

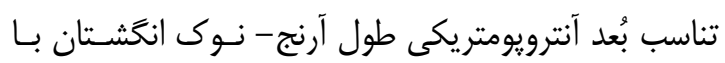

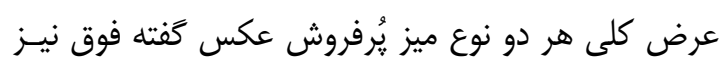

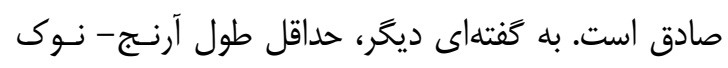

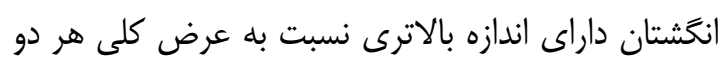

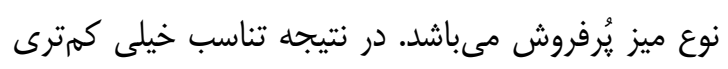
(نزديك به صفر) مشاهده شد.

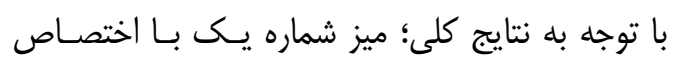

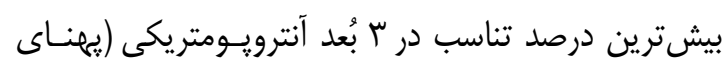

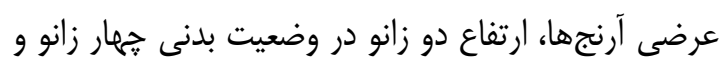

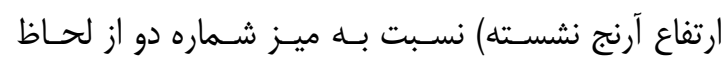

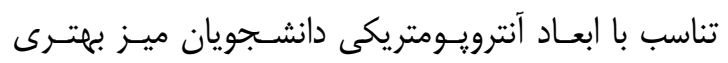
مىباشد. بنابراين طراحان و مهندسين بايد براى اطمينـان

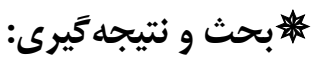

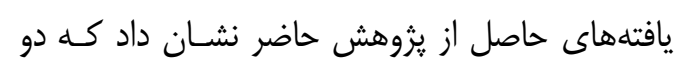

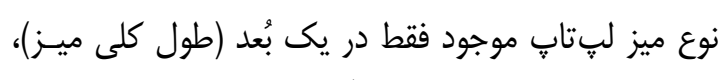

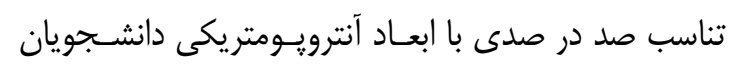

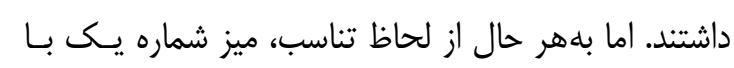

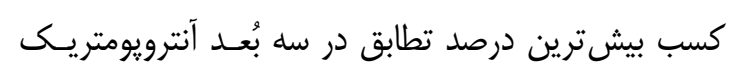
بهتر از ميز شماره دو بود. در اين مطالعه، درصد تناسب ابعاد آنترويومتريكى، طول

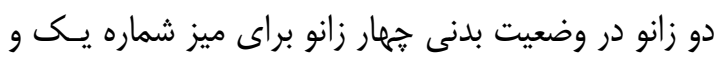

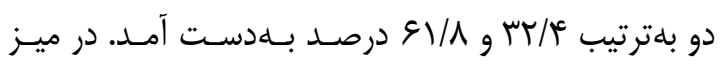

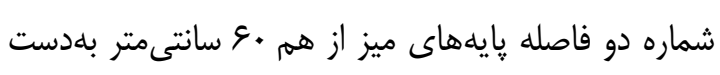

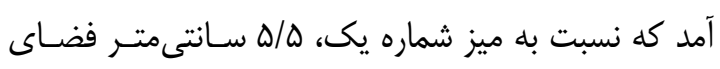

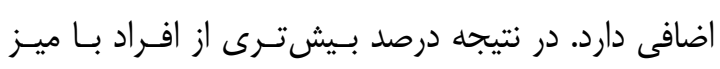
شماره دو تناسب خواهند داشت.

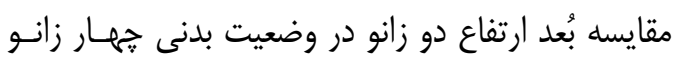

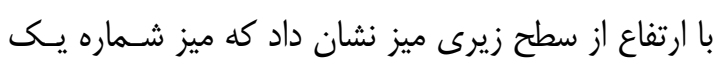

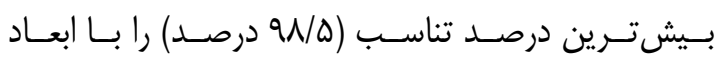

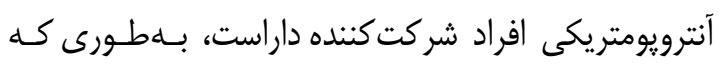

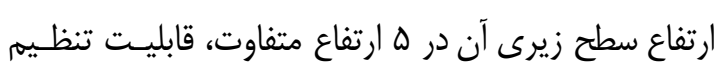

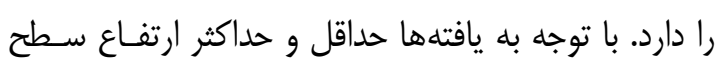

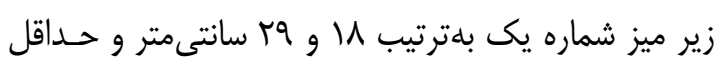

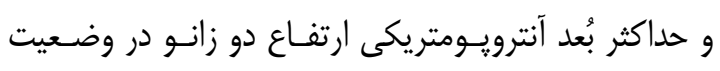

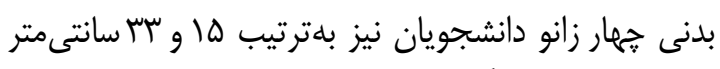

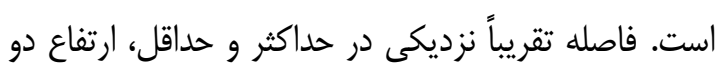

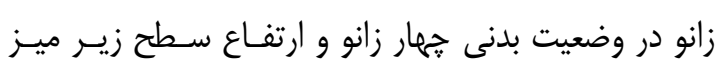

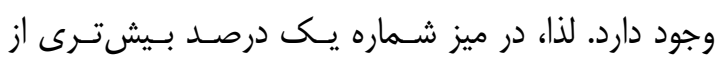

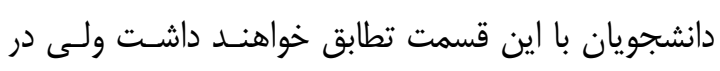

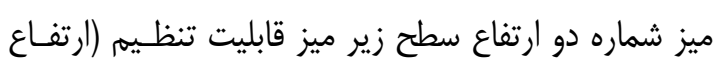
ثابت \) اسانتىمتر) را ندارد.

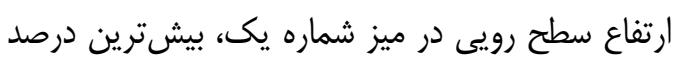

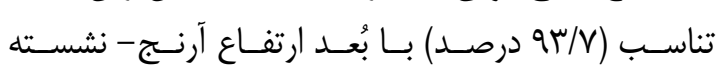

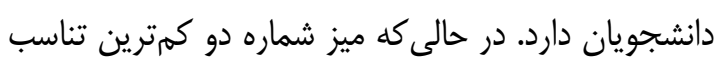

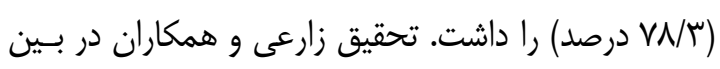

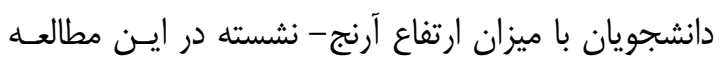


4. Motamedzadeh M, Hassan Beigi MR, Choobineh AR, Mahjoob H. Design and development of an ergonomic chair for Iranian office workers. J Zanjan Univ Med Sci 2009; 17(68): 45-52. [In Persian]

5. Dianat I, Haslegrave CM, Stedmon AW. Design options for improving protective gloves for industrial assembly work. Appl Ergon 2014; 45(4): 1208-17. doi: 10.1016/j. apergo.2014.02.009.

6. Ghaderi E, Maleki A, Dianat I. Design of combine harvester seat based on anthropometric data of Iranian operators. Int J Ind Ergonom 2014; 44(6): 810-6. doi: 10. 1016/j.ergon.2014.10.003.

7. Heidarimoghadam R, Motamedzade $M$, Roshanaei G, Ahmadi R. Match between school furniture dimensions and children's anthropometric dimensions in male elementary schools. J Ergon 2014; 2(1): 9-18. [In Persian]

8. Mahoney JM, Kurczewski NA, Froede EW. Design method for multi-user workstations utilizing anthropometry and preference data. Appl Ergon 2015; 46 Pt A: 60-6. doi: 10.1016/j.apergo.2014.07.003.

9. Soares MM. Translating user needs into product design for the disabled: an ergonomic approach. Theoretical Issues in Ergonomics Science 2012; 13(1): 92-120. doi: 10.1080/ 1463922X.2010.512989.

10. Daneshmandi H, Isanezhad A. The proportion of the equipments used by students and ergonomic standards and their anthropometrical characteristics. Research on Sport Science 2005; 3(7): 73-90.

11. Choobineh AR, Rahimi Fard H, Jahangiri M, Mahmood Khani S. Musculoskeletal injuries and their associated risk factors in office work. Iran Occup Health 2012; 8(4): 70-81. [In Persian]
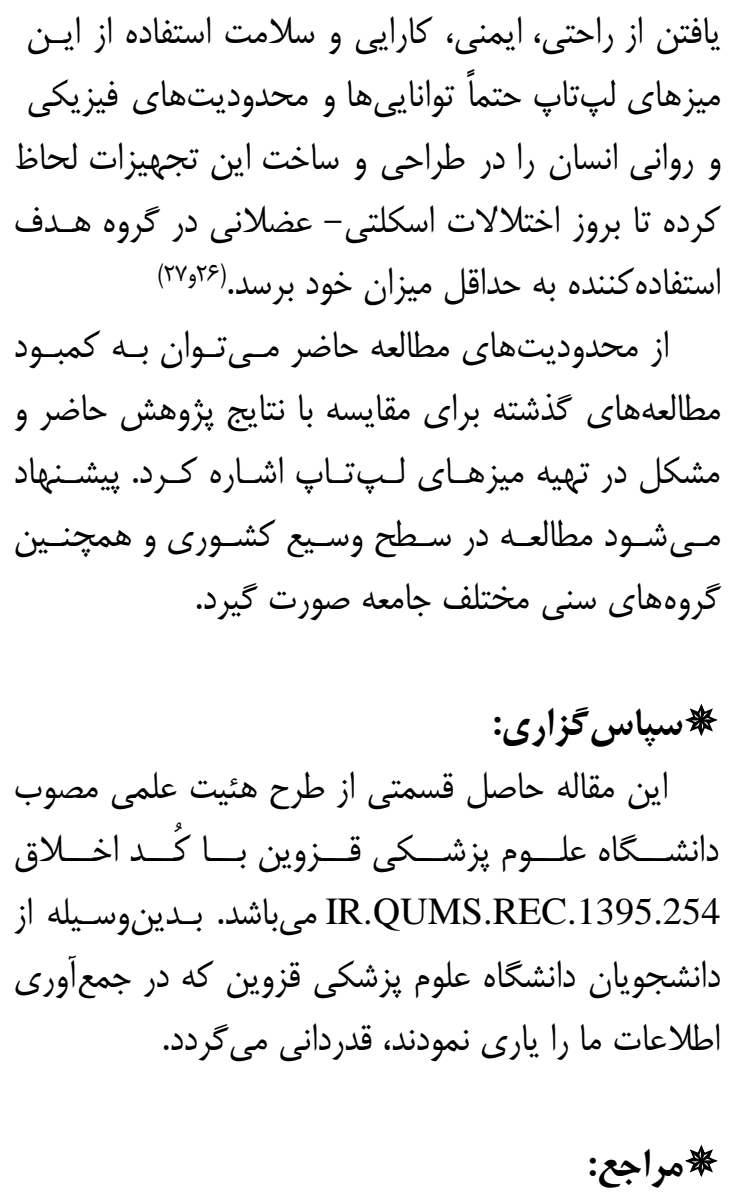

1. Shokoohi H, Khoshroo M. Fitness measurement of the combat troops to prevent the skeleton and muscular disorders due to inappropriate design of the military equipments. Annals Miltary Health Sci Res 2011; 9(3): 172-7. [In Persian]

2. Hough R, Nel M. Time and space dimensions of computer laptop use amongst third year students of the University of the Free State. S Afr J Occup Ther 2016; 46(1): 27-32. doi: org/10.17159/2310-3833/2016/ v46n1a7.

3. Sauer J, Wiese BS, Rüttinger B. Improving ecological performance of electrical consumer products: the role of design-based measures and user variables. Appl Ergon 2002; 33(4): 297-307. doi: 10.1016/S00036870(02)00017-0. 
12. Jamjumrus N, Nanthavanij S. Ergonomic intervention for improving work postures during notebook computer operation. J Hum Ergol (Tokyo) 2008; 37(1): 23-33.

13. Moras R, Gamarra T. A survey of ergonomic issues associated with a university laptop program. J Edu Human Dev 2007; 1(2): 1-15.

14. Shokri S, Qhalenoy M, Taban E, Ahmadi O, Kouhnavard B. Evaluation of prevalence of musculoskeletal disorders among students using portable computer in faculty of health, Qazvin University of Medical Sciences. J Health Res Community 2015; 1(3): 9-15. [In Persian]

15. Jafarvand M, Marandi N, Varmazyar S, Mohammadi E. Investigation of student's satisfaction from the laptop desks using satisfaction questionnaire. J Qazvin Univ Med Sci 2018; 22(1): 52-60. [In Persian]

16. Bowman PJ, Braswell KD, Cohen JR, Funke JL, Landon HL, Martinez PI, et al. Benefits of laptop computer ergonomics education to graduate students. Open $\mathrm{J}$ Therapy and Rehabilitation 2014; 2(1): 25-32. doi: 10.4236/ojtr.2014.21006.

17. Jalil S, Nanthavanij S. Analytical algorithms for ergonomic seated posture when working with notebook computers. Industrial Engineering and Management Systems 2007; 6(2): 146-57.

18. Berkhout AL, Hendriksson-Larsen K, Bongers P. The effect of using a laptopstation compared to using a standard laptop PC on the cervical spine torque, perceived strain and productivity. Appl Ergon 2004; 35(2): 14752. doi: 10.1016/j.apergo.2003.11.008.

19. Straker L, Jones KJ, Miller J. A comparison of the postures assumed when using laptop computers and desktop computers. Appl Ergon 1997; 28(4): 263-8. doi: 10.1016/S0003-6870(96)00073-7. 20. Sommerich CM, Starr H, Smith CA, Shivers C. Effects of notebook computer configuration and task on user biomechanics, productivity, and comfort. Int $\mathrm{J}$ Ind Ergon 2002; 30(1): 7-31. doi: 10.1016/S0169-8141 (02)00075-6.

21. Moffet H, Hagberg M, Hansson-Risberg E, Karlqvist L. Influence of laptop computer design and working position on physical exposure variables. Clin Biomech (Bristol, Avon) 2002; 17(5): 368-75. doi: 10.1016/ S0021-9290(02)00062-3.

22. Straker L, Pollock C, Burgess-Limerick R, Skoss R, Coleman J. The impact of computer display height and desk design on muscle activity during information technology work by young adults. J Electromyogr Kinesiol 2008; 18(4): 606-17. doi: 10.1016/j.jelekin.2006.09.015.

23. Sohrabi MS, Aliari S, Keshavarz Z, Alijani S, Torkzadeh F, Aghaee R. Design and Development of an Ergonomic Kharak by using students' anthropometric characteristics of Isfahan University of Art. J Health Syst Res 2014; 9(12): 1301-10. [In Persian]

24. Zarei F, Rajaei B, Nikpey A, Varmazyar S, Safari-Variani A. Review the proportion of university seats with body dimensions of students at the School of Public Health of Qazvin University of Medical Sciences in 1388. Iran Occup Health 2011; 8(3): 39-47. [In Persian]

25. Ghofrani M, Noori H, Roshan bakhsh Yazdi A. Assessing the appropriateness of educational furniture with body size of students in Yazd. J Ergon 2014; 2(3): 77-87. [In Persian]

26. Sharifi Z, Osqueizadeh R, Tabatabai Ghomshe F. Ergonomic redesign of industrial chair. J Ergon 2015; 3(1): 1-9. [In Persian] 
27. Tirgar A, Aghalari Z, Salari F. among medical sciences students. J Ergon Musculoskeletal disorders and awareness of 2014; 1(3): 55-64. [In Persian]

ergonomic considerations in computer use 